\title{
GAYA HIDUP ELITE MINANGKABAU DI AFDEELING AGAM (1837-1942)
}

\author{
THE LIFE STYLE OF MINANGKABAU ELITE \\ IN AFDEELING AGAM (1837-1942)
}

\author{
Dwi Vina Lestari, Nina Herlina Lubis, R.M. Mulyadi \\ Program Studi Ilmu Sejarah, Fakultas Ilmu Budaya, Universitas Padjadjaran \\ Jalan Raya Bandung Sumedang Km. 21 Jatinangor \\ e-mail: dwi.vinalestari@gmail.com, nina.herlina@unpad.ac.id,r.m.mulyadi@unpad.ac.id
}

\begin{abstract}
Abstrak
Elite Minangkabau di Afdeeling Agam mengalami perubahan, baik meliputi status, kekuasaan, maupun sumber penghasilan. Hal tersebut terjadi bersamaan dengan ditetapkannya kebijakan politik Pemerintahan Hindia Belanda di Sumatera Barat (1837-1942). Untuk menjabarkan persoalan tersebut diperlukan kajian historis menggunakan metode sejarah, terdiri atas heuristik, kritik, interpretasi, dan historiografi. Selain itu, untuk menghasikan karya yang bersifat analitis, dilakukan pendekatan ilmu antropologi dan sosiologi politik. Berdasarkan penelitian yang dilakukan, gaya hidup elite Minangkabau di Afdeeling Agam pada 1837-1942 tidak mengalami perubahan seutuhnya, melainkan terjadi akulturasi budaya asli Minangkabau dengan budaya Barat. Umumnya, gaya hidup elite tradisional Minangkabau yang menduduki jabatan kolonial mencerminkan statusnya sebagai pegawai pemerintah dan pemimpin sukunya masing-masing, sedangkan gaya hidup elite intelektual lebih banyak menyerap budaya Barat. Meskipun demikian, baik elite tradisional maupun elite intelektual tetap menunjukkan cirinya sebagai orang Minangkabau, dapat diperhatikan dari agama dan tradisi adat yang tetap dilakukan hingga saat ini.
\end{abstract}

Kata kunci: elite tradisional Minangkabau, elite intelektual, Afdeeling Agam.

\begin{abstract}
Minangkabau Elite in Afdeeling Agam has been changed, including status, power, and income sources. It coincided with the enactment of the Dutch East Indies government policy in West Sumatra (1837-1942). To describe these issues, it needs historical study by using the historical method; it consists of heuristics, criticism, interpretation, and historiography. In addition, to generate the analytical work, the writer does anthropology and political sociology approach. Based on the research, Minangkabau elite lifestyle in Afdeeling Agam in 1837-1942 did not change completely, but there were an acculturation between native Minangkabau and Western culture. Generally, the traditional Minangkabau elite lifestyle which has colonial positions reflected its status as government officials and leaders of their own people. Meanwhile, the intellectual elite lifestyle absorbed Western culture. Nonetheless, both the traditional elite and intellectual elite continued to show the character as the Minangkabau, it can be considered from the religious and customary traditions which are still being done until today.
\end{abstract}

Keywords: Minangkabau Traditional elite, intellectual elite, afdeeling Agam.

\section{A. PENDAHULUAN}

Minangkabau identik dengan wilayah administratif Provinsi Sumatera Barat saat ini, ditambah Kabupaten Kampar dan Kuantan di Provinsi Riau, serta dikurangi Kepulauan Mentawai
(Asnan, 2003: xv). Agam, yang menjadi batasan spasial dalam penelitian ini merupakan bagian dari Sumatera Barat. Wilayah tersebut terletak di kaki Gunung Merapi dan Gunung Singgalang. Sejak Belanda memperkenal- kan sistem 
pemerintahannya, Agam memperoleh kedudukan sebagai daerah administratif setingkat afdeeling dengan ibu kota Fort de Kock (Asnan, 2003: 12).

Masyarakat

Minangkabau menganut sistem demokrasi. Strata sosial hanya berlaku dalam sebuah desa sehingga dikenal tiga lapisan masyarakat, yaitu bangsawan, orang biasa, dan orang paling rendah (Junus, 1999: 158). Sementara itu, stratifikasi sosial di Pedalaman Sumatera Barat dibedakan berdasarkan tempat tinggal sehingga dikenal keluarga pendiri kampung, pendatang yang mempunyai hak, dan pendatang yang tidak mempunyai hak (Josselin, 1975: 11). Meskipun demikian, banyak peneliti yang setuju bahwa orang pertama pendiri nagari (bentuk khusus wilayah pemerintahan menurut sistem hukum adat Minangkabau) memiliki status lebih tinggi. Mereka mempunyai tanah yang lebih luas sehingga berbeda dengan masyarakat pada umumnya (Kato, 2005: 50).

Sebelum Belanda berkuasa di Sumatera Barat, masyarakat Minangkabau tidak mengenal struktur politik pemerintahan yang lebih tinggi dari nagari (Zulqayyim, 2006: 39). Tiap nagari bebas, berdiri sendiri, dan tidak memiliki hubungan dengan nagari-nagari tetanggga, kecuali untuk keamanan bersama. Sistem pemerintahan nagari tetap bertahan hingga dekade kedua abad ke-19. Dalam sistem pemerintahan ini, penghulu adalah ningrat, jabatan dengan hak istimewa dan gelar datuak yang digunakannya. Situasi tersebut menyulitkan Belanda menerapkan sistem politik kolonialnya. Untuk itu, dibentuk sistem pemerintahan supra nagari (Amran, 1986: 187; Zulqayyim, 2006: 39-40; Mansoer, et al., 1970: 13).

Dalam sistem pemerintahan yang baru, Belanda membentuk jabatan baru di luar adat, di antaranya kepala laras (larashoofd), penghulu kepala, dan penghulu suku rodi. Umumnya, mereka berasal dari elite penghulu tradisional nagari yang sedang berkuasa. Meskipun menyandang gelar baru, kekuasaannya terbatas pada daerah asal (Kato, 2005: 100).

Pada 1914, sistem laras diganti dengan sistem distrik yang dikepalai oleh demang. Berbeda dengan kepala laras, seorang demang dipilih berdasarkan tingkat pendidikan dan kemampuannya (Zulqayyim, 2006: 47). Selain itu, juga terdapat elite intelektual. Golongan tersebut muncul akibat berkembangnya pendidikan Barat di Sumatera Barat.

Kedudukan elite intelektual dan elite tradisional Minangkabau di Afdeeling Agam membawa perubahan politik dan sosial. Status sosial yang tinggi menentukan gaya hidup mereka. Pada hakikatnya, gaya hidup memuat suatu eksklusivisme yang menonjolkan adanya perbedaan status. Perbedaan tersebut sering dilambangkan sebagai larangan bagi suatu golongan dan hak istimewa bagi golongan tertentu (Kartodirdjo, et al., 1993: 53; Lubis, 1998: 3). Untuk itu, gaya hidup dapat dijadikan sebagai salah satu cara untuk melihat perubahan kedudukan dan kekuasaan elite Minangkabau di Afdeeling Agam pada masa Pemerintahan Hindia Belanda yang dibahas dalam penelitian ini.

Pada penelitian terdahulu, Graves (2007) mengungkapkan tentang reaksi bumiputra terhadap kekuasaan kolonial Belanda di Minangkabau, khususnya berkenaan dengan perkembangan abad ke19; Reid (2012) menguraikan pertikaian kelas, konflik, bentrok agama sebagai titik balik menghilangnya kaum bangsawan, raja dan sultan Aceh, sekaligus sebagai tanda dimulainya perputaran sejarah modern di Sumatera; Sjarifoedin (2011) memaparkan sejarah Minangkabau, mulai dari awal berdirinya Minangkabau, Kerajaan Minangkabau, Adityawarman, Kerajaan Pagaruyung, masuk dan berkembangnya Islam, hingga kebangkitan Islam; Hadler (2010) mendeskripsikan mengenai sejarah ringkas Perang Paderi, berakhirnya Perang Paderi hingga kekalahan Tuanku Imam Bonjol, masuknya Sumatera Barat ke dalam Hindia 
Timur Belanda, perdebatan tentang fisik rumah, konsep keluarga, pendidikan anakanak dalam masyarakat Minangkabau, gagasan moralitas dan peran perempuan pada awal abad ke-20, serta kontroversi publik antara matriarkat, Islam reformis, dan progresivisme yang mendominasi pergerakan masyarakat Minangkabau; Manan (1984) membahas tentang kehidupan penghulu andiko sebagai elite tradisional di Minangkabau; Lubis (1998) menjelaskan berbagai aspek kehidupan Kaum Menak Priangan pada 1800-1942, terutama berkaitan dengan gaya hidup Kaum Menak yang meliputi gelar dan nama, tempat tinggal, etiket dan bahasa, pusaka dan upacara, pendidikan, perkawinan dan konkubinasi, kesenian dan rekreasi, kebiasaan makan, serta agama dan kepercayaan. Penjelasan tersebut dijadikan sebagai model dalam penelitian ini dengan objek penelitian, batasan spasial dan temporal yang berbeda. Penelitian ini membahas dinamika gaya hidup elite Minangkabau di Afdeeling Agam tahun 1837-1942. Tahun 1837 dijadikan sebagai titik awal penelitian, berkaitan dengan pembentukan Gouvernement Sumatra's Westkust melalui Besluit Gouvernement Kommissaris Cochius pada 29 November 1837 dan jatuhnya benteng terakhir Paderi di Bonjol. Jatuhnya benteng tersebut dianggap petinggi sipil dan militer Belanda di daerah tersebut sebagai awal baru dari kekuasaan mereka (Asnan, 2006: 43-44). Tahun 1942 sebagai titik akhir penelitian berkaitan dengan berakhirnya masa Pemerintahan Hindia Belanda di Sumatera Barat.

Keluarga elite tradisional terkemuka di Afdeeling Agam yang dijadikan objek penelitian ini, yaitu Yahya Datuak Kayo dari Koto Gadang, Djaa Datuak Batuah dari Tilatang, dan Sulaiman Datuak Tumangguang (Datuak Tumangguang Sutan Sulaiman) dari Sungai Puar. Sementara itu, elite intelektual yang dimaksud di antaranya, Haji Agus Salim, Sutan Sjahrir, Abdul Muis, dan Mohammad Hatta.

\section{B. METODE PENELITIAN}

Penelitian ini menggunakan metode sejarah yang terdiri atas heuristik, kritik, interpretasi, dan historiografi. Tahapan pertama dari metode sejarah adalah heuristik, merupakan tahapan atau kegiatan menemukan dan menghimpun sumber, informasi, jejak masa lampau (Herlina, 2008: 7-15). Setelah sumber terhimpun, dilakukan tahapan kedua, yaitu kritik, terdiri atas kritik eksternal dan kritik internal. Kritik eksternal dilakukan dengan meneliti keaslian sumber dan kritik internal dengan meneliti kredibilitas sumber (Kuntowijoyo, 2013: 77-78).

Sumber yang telah dikritik belum dianggap sebagai fakta sejarah. Untuk itu, perlu dilakukan koroborasi suatu sumber sejarah dengan sumber lain yang bersifat merdeka sehingga menghasilkan fakta yang mendekati kepastian (centainty fact). Jika koroborasi tidak bisa dilakukan, berlaku prinsip argumentum ex silentio, sumber yang berisi data dianggap sebagai fakta (Gottschalk, 2008: 130; Herlina, 2008: 34-35).

Tahapan ketiga disebut interpretasi, terdiri atas analisis (menguraikan) dan sintesis (menyatukan). Untuk itu, pada tahapan ini, penulis harus mengambil jarak dengan sumber agar tidak terlalu dekat dan menimbulkan bias. Dalam hal ini dikenal beberapa jenis interpretasi, yaitu interpretasi verbal, teknis, logis, psikologis, dan faktual. Selanjutnya, tahapan akhir dari metode sejarah disebut historiografi (Herlina, 2008: 36-60).

Penjelasan yang bersifat analitis diperoleh melalui pendekatan ilmu antropologi dan sosiologi politik. Pendekatan antropologi dapat mempertajam analisis, menyangkut status sosial dan gaya hidup, serta aspek-aspek yang berkaitan dengan kedua unsur kultural tersebut, termasuk meneliti latar belakang budaya sehingga melahirkan suatu prilaku politik. Pendekatan sosiologi politik digunakan untuk menjelaskan hubungan antara status dan kekuasaan, masalah 
otoritas, hubungan-hubungan sosial, dan masalah birokrasi (Lubis, 1998: 12). Selain itu, penulis juga menggunakan konsep gaya hidup dan elite.

Gaya hidup (style of life) mengandung pengertian yang meliputi karakteristik, kekhususan, dan tata cara dalam kehidupan suatu golongan masyarakat. Lebih lanjut dijelaskan, gaya hidup menunjukkan bagaimana orang mengatur kehidupan pribadinya, hidup bermasyarakat, bertingkah laku di depan umum, dan membedakan statusnya dari orang melalui lambang-lambang. Adapun aspek-aspek yang berkaitan dengan gaya hidup, di antaranya gelar dan nama, pakaian, tempat tinggal, etika dan bahasa, pusaka, upacara yang dijalankan selama hidup, pendidikan, perkawinan dan konkubinasi, ikatan kekerabatan, serta kesenian dan rekreasi (Lubis, 1998: 4 \& 153). Dalam hal ini, gaya hidup dijadikan sebagai petunjuk utama dari status (Kartodirdjo, et al., 1993: 53). Oleh karena itu, dalam penelitian ini konsep gaya hidup dan aspek-aspeknya digunakan untuk menguraikan perubahan kedudukan dan kekuasaan elite Minangkabau di Afdeeling Agam sehingga bisa membedakannya dengan masyarakat kebanyakan. Sementara itu, konsep elite digunakan untuk menjelaskan kedudukan penghulu sebagai elite tradisional Minangkabau yang dianggap sebagai keluarga pendiri kampung dan pegawai Pemerintah Belanda di Sumatera Barat, serta elite intelektual sebagai elite baru.

Istilah elite berasal dari bahasa latin "eligere" yang berarti "memilih". Kata ini digunakan pada abad ke-17 untuk menggambarkan barang-barang dengan kualitas yang sempurna, penggunaannya, kemudian diperluas untuk merujuk pada kelompok-kelompok sosial unggul. Menurut Oxford English Dictionary, kata elite digunakan sejak 1823 untuk kelompok-kelompok sosial (Bottomore, 2006: 1).

Pareto menjelaskan bahwa setiap cabang kegiatan manusia memiliki elite.
Pada hakikatnya, seorang elite mampu berdiri pada puncak piramida cabang kegiatannya. Ia membagi kelas elite menjadi dua kelompok, yaitu elite yang memerintah (governing elite) dan elite yang tidak memerintah (non-governing elite). Elite memerintah terdiri dari individu-individu yang secara langsung atau tidak langsung memainkan peranan besar dalam pemerintahan, sedangkan elite yang tidak memerintah merupakan sisanya. Kemudian, Gaetano Mosca menjelaskan bahwa dalam setiap masyarakat dijumpai dua kelas, yaitu kelas yang berkuasa dan kelas yang dikuasai. Kelas pertama jumlahnya jauh lebih sedikit, melaksanakan fungsi politik, monopoli kekuasaan dan menikmati keistimewaan yang diberikan oleh kekuasaan. Sementara itu, kelas yang kedua jumlahnya lebih banyak, diperintah, dan dikendalikan oleh yang pertama. Meskipun demikian, baik Pareto maupun Mosca memusatkan perhatian pada elite dalam artian kelompok-kelompok yang secara langsung menggunakan atau berada dalam posisi yang memberikan pengaruh kuat terhadap penggunaan kekuataan politik. Pada saat yang sama, mereka menyadari bahwa elite memerintah atau kelas politik terdiri dari kelompok-kelompok sosial berbeda (Bottomore, 2006: 2-5).

\section{HASIL DAN BAHASAN \\ 1. Afdeeling Agam Abad XIX hingga Awal Abad XX}

Daerah Dataran Tinggi Agam disebut juga dengan Luhak Agam (Mansoer, et al., 1970: 2-3; Navis, 1986: 28; Zulqayyim, 2006: 7). Wilayah tersebut terletak di kaki Gunung Merapi dan Singgalang (Asnan, 2003: 12). Sebelah utara, Agam berbatasan dengan Kabupaten Pasaman, di timur laut dengan Kabupaten Limapuluh Koto, di timur dengan Kabupaten Tanah Datar, di selatan dengan Kabupaten Padang Pariaman, serta di bagian barat dan tenggara menghadap ke Lautan Hindia (Ensiklopedi Nasional Indonesia Jilid 1, 1988: 123). 
Keadaan alam Agam cukup beragam dan subur. Pantai baratnya berupa dataran rendah subur dengan budi daya kelapa dan makin ke timur tanahnya subur. (Ensiklopedi Nasional Indonesia jilid 1, 1988: 123). Wilayah tersebut dilalui banyak sungai, bersumber dari pinggang Gunung Merapi, dua di antaranya Batang Agam dan Batang Tambuo yang melewati Bukittinggi (Zulqayyim, 2006: 15). Sungai-sungai tersebut digunakan untuk mengairi sawah dan ladang para petani.

Perbedaan bentuk wilayah Agam mengakibatkan beraneka ragam kehidupan perekonomian masyarakatnya. Nagarinagari yang terletak di kaki Gunung Merapi dan Gunung Singgalang disebut desa perbukitan (Canduang, Sungai Pua, Pandai Sikek, Koto Gadang, Guguak, Malalak, Balingka, Matua, dan Kamang). Penduduk yang mendiami nagari-nagari tersebut memenuhi kebutuhan hidup dengan menanam tanaman keras (kopi, indigo, dan kulit manis) dan sayur-sayuran (kentang dan buncis). Sementara itu, nagari-nagari yang terletak di daerah lembah disebut desa persawahan (IV Angkek, Kapau, dan Tilatang). Meskipun demikian, sebagian dari masyarakat Agam bergerak dalam industri rumah tangga dan perdagangan (Zulqayyim, 2006: 15-16).

Sebelum Belanda datang ke

Sumatera Barat, daerah Agam telah berhubungan dengan pantai barat, terutama Pariaman untuk mendapatkan garam dan ikan kering (Asnan, 2003: 12). Kedatangan Belanda untuk kedua kalinya pada 1819 , mengakibatkan Agam memperoleh kedudukan sebagai daerah administratif setingkat afdeeling.

Pada 1837, Agam merupakan bagian dari wilayah Afdeeling van Padangsche Bovenlanden. Dalam perkembangannya, pada 1841, Agam memiliki status administratif setingkat afdeeling dan bagian dari Residentie Padangsche Bovenlanden. Saat itu, Afdeeling Agam terbagi atas beberapa onderafdeeling, yaitu Oud Agam, Danau Districten en Matoer, VIII Koto en VII
Lurah, dan Bonjol. Masing-masing onderafdeeling terdiri atas beberapa kelarasan dan setiap kelarasan terdiri atas beberapa nagari sebagai satuan politik terkecil. Pada 1913, dilakukan kembali reorganisasi wilayah administratif, sehingga keberadaan Residentie Padangsche Bovenlanden dan Padangsche Benedenlanden dihapuskan. Sejak saat itu, Afdeeling Agam langsung berada di bawah Residentie Sumatra's Westkust (Asnan, 2006: 32-79; Regeeringsalmanak voor Nederlandsch-Indie 1884-1942).

Penduduk Afdeeling Agam mengalami peningkatan setiap tahunnya. Pada 1852 berjumlah 197.217 jiwa, terdiri atas 30 Eropa, 196.927 pribumi, 49 Cina, dan 21 budak (Graves, 2007: 92). Pada 1920, mengalami peningkatan menjadi 353.823 jiwa, terdiri atas 438 Eropa, 352.529 pribumi, 688 Cina, dan 168 bangsa lain. Sementara itu, berdasarkan sensus penduduk tahun 1930, jumlah penduduk di wilayah tersebut meningkat menjadi 434.209 jiwa, terdiri atas 693 Eropa, 431.997 pribumi, 1.208 Cina, 311 lainnya yang tersebar di Onderafdeeling Ophir, Lubuaksikaping, Oud Agam, dan Maninjau. Dengan demikian, penduduk terbanyak berada di Onderafdeeling Oud Agam dengan 191.707 jiwa penduduk dan paling kecil berada di Onderafdeeling Lubuk Sikaping dengan 51.553 jiwa penduduk (Volkstelling 1930, 1935: 113).

\section{Elite Minangkabau di Afdeeling Agam (1837-1942)}

Elite Minangkabau yang dibahas dalam penelitian ini terdiri atas elite tradisional dan elite intelektual. Elite tradisional (penghulu) merupakan seorang laki-laki yang dituakan dalam suku di Minangkabau dan diberi gelar datuak. Ia bertanggung jawab serta berkewajiban memelihara anggota kaum, suku, dan nagari (Sjarifoedin, 2011: 140, Asnan, 2003: 243). Pada masa kolonial, sebagian besar penghulu menduduki jabatan dalam birokrasi Pemerintahan Hindia Belanda. Sementara itu, ciri utama dari elite 
intelektual adalah seorang tamatan sekolah sekuler, tetapi tidak dapat ditemukan di nagari asalnya karena mereka telah merantau (Graves, 2007: 241).

Elite tradisional Minangkabau di Afdeeling Agam yang dijadikan objek penelitian, di antaranya Sulaiman Datuak Tumangguang, Yahya Datuak Kayo, dan Djaa Datuak Batuah. Sulaiman Datuak Tumangguang adalah seorang Kepala Laras Sungai Puar (1870-1930). Ia merupakan kepala laras terkemuka di Minangkabau dan dikenal sangat dekat dengan Belanda (Suryadi, 2016). Yahya Datuak Kayo adalah Kepala Laras IV Koto terakhir (Etek, et al., 2007: 6, 187-204; Etek, et al., 2008: 1-6). Sementara itu, Djaa Datuak Batuah diangkat menjadi Kepala Distrik (districtshoofd) kelas 1 Tilatang pada 7 Juni 1923. Keluarganya merupakan keturunan kepala laras suduik basuik dan cukup berpengaruh di Minangkabau (Suryadi, 2016).

Elite intelektual di Afdeeling Agam berada di nagari-nagari kecil yang berada di kawasan perbukitan sekitar Bukittinggi (Graves, 2007: 245). Bukittinggi merupakan kota kelahiran Mohammad Hatta. Ia merupakan anak dari Haji Mohammad Djamil (Syekh Batuhampar, ulama Minangkabau). Sementara itu, berbagai unsur yang mendorong minat pendidikan sekuler di kawasan Dataran Tinggi Sumatera Barat terkonsentrasi di Koto Gadang. Wilayah tersebut dikenal sebagai tempat lahirnya tokoh nasionalis, seperti Haji Agus Salim, Sutan Sjahrir, dan Abdul Muis. Haji Agus Salim adalah anak dari Sutan Mohammad Salim (hoofdjaksa Riau en Onderhorigheden) dan Sutan Sjahrir adalah anak dari Mohammad Rasyad gelar Maharaja Soetan (pernah menjadi juru tulis di Alahan Panjang, hoofdjaksa di Talu, Rao, Padang Panjang, dan Medan). Abdul Muis merupakan anak Sulaiman Datuak Tumangguang (Kepala Laras Sungai Puar), tetapi ibunya berasal dari Koto Gadang.

\section{Gaya Hidup Elite Minangkabau di Afdeeling Agam (1837-1942) \\ a) Nama dan Gelar}

Laki-laki

Minangkabau

menggunakan nama pemberian orang tua dari lahir hingga usia tertentu dan setelah menikah ia akan mendapatkan gala (gelar). Hal tersebut sesuai dengan pepatah ketek banamo, gadang bagala (Navis, 1986: 132). Dengan kata lain, laki-laki Minangkabau menggunakan nama pemberian orang tua dari lahir hingga usia tertentu, setelah dewasa dan menikah ia mendapatkan gelar, sehingga nama aslinya tidak digunakan lagi.

Gelar di Minangkabau dibedakan menjadi gala pusako (gelar pusaka) dan gala buatan (gelar buatan), serta gala bapangkat (gelar berpangkat) dan gala mudo (gelar muda). Gelar pusaka merupakan gelar sebenarnya yang diturunkan berdasarkan sistem matrilineal; gelar buatan ditetapkan melalui persetujuan keluarga induak (induk); gelar berpangkat menggunakan titel datuak yang diturunkan berdasarkan sistem matrilineal; dan gelar muda menggunakan titel sutan. Ukuran tua atau muda di Agam ditentukan oleh kelahiran seorang cucu. Orang yang belum memiliki cucu dianggap masih muda dan sebaliknya (Mansveld, 1876: 450-451).

Pada masa Pemerintahan Hindia Belanda, orang-orang yang memiliki jabatan tinggi, seperti kepala laras, penghulu kepala, kepala nagari, penghulu suku rodi, demang, dan asisten demang, terkadang menggunakan gelar datuak sebagai sebuah penghormatan, tetapi tidak bisa diwariskan (Navis, 1986: 135). Sebagian besar yang menduduki jabatan tersebut berasal dari kalangan adat yang berkedudukan sebagai seorang penghulu. Meskipun mereka menyandang gelar-gelar baru di luar adat, kekuasaannya masih terbatas pada daerah asal dan tidak bisa dipindahkan ke tempat lain (Kato, 2005: 100).

Umumnya, pemberian gelar di Minangkabau sama. Salah satu contoh 
dapat diperhatikan dari pemberian gelar kepada Yahja Datuak Kayo. Yahya menerima gelar Datuak Kayo saat berumur 20 tahun 9 bulan, setelah pamannya, Landjadin Khatib Besar gelar Datuak Kayo meninggal dunia. Kedudukan Yahya sebagai seorang penghulu suku di Koto Gadang, memberikannya kesempatan untuk menduduki jabatan kepala laras. Setelah dilakukan beberapa proses pemilihan, melalui Besluit Gubernur Sumatera Barat 11 Mei 1895, Yahya Datuak Kayo resmi diangkat menjadi Kepala Laras IV Koto. Saat sistem kelarasan diganti dengan sistem demang, Yahya tetap menduduki jabatan dalam birokrasi Pemerintahan Belanda sebagai Demang Bukittinggi (1914), Demang Payakumbuh (1915), Demang Padang Panjang (1919-1928), dan Demang Air Bangis pada tahun 1927 (Etek, et al., 2007: 187-189; Etek, et al., 2008: 3-4). Meskipun demikian, selama menduduki jabatanjabatan tersebut, ia tetap menggunakan gelar datuak sebagai gelar pusaka. Namun, dalam kesehariannya, saat menjabat sebagai kepala laras ia dipanggil dengan angku lareh, sedangkan saat menjabat sebagai demang dipanggil dengan angku demang.

Berbeda dengan elite intelektual, Haji Agus Salim, Sutan Sjahrir, Abdul Muis, dan Mohammad Hatta tidak menggunakan gelar sesuai ketentuan adat Minangkabau. Mereka menggunakan nama pemberian orang tua sebagai identitasnya. Hal tersebut berkaitan dengan tradisi merantau dan pendidikan Barat yang dijalaninya. Meskipun demikian, gelar sutan di depan nama Sjahrir adalah pemberian orang tuanya (Mrazek, 1996: 8). Berbeda dengan Hatta, ia tidak menggunakan gelar dan tidak mengetahui sukunya. Menurut kakek Hatta, hal tersebut berkaitan dengan tradisi merantau yang dilakukannya sejak umur 19 tahun dan baru kembali setelah 13 tahun kemudian (Hatta, 1982: 268-271).

\section{b) Tempat Tinggal}

Rumah gadang merupakan bangunan terpenting di Minangkabau. Rumah gadang dikatakan gadang (besar) bukan dilihat dari fisiknya, melainkan karena memiliki fungsi yang besar (Navis, 1986: 176-177). Bangunan tersebut terbuat dari kayu, didirikan di atas panggung, atapnya membungkuk berbentuk pelana, biasanya memiliki empat gonjong atau lebih, ruang bagian bawah, dan ukuran ditentukan oleh jumlah keluarga yang mendiaminya (Joustra, 1920: 166).

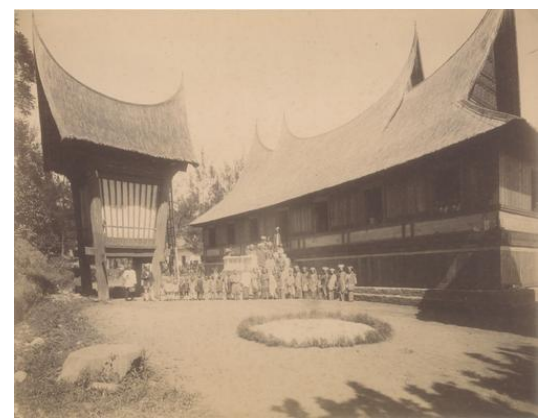

Gambar 1. Rumah Gadang dan Gudang Beras Kepala Laras Sungai Puar

Sumber: Joustra, M, 1920: 167

Atap rumah gadang dibuat sejajar dengan jalan berdirinya rumah dan dibengkokkan dalam bentuk tanduk kerbau. Atap khas Minangkabau juga ditemukan pada lumbung padi (rangkiang), rumah tabuah, dan balai adat. Dalam hal ini, rumah gadang bangsawan memiliki lebih dari dua gonjong, biasanya empat atau enam. Di daerah Silungkang, Sulit Air, dan Koto Gadang, ruang bagian bawah digunakan untuk menenun. Selain itu, bangunan rumah gadang memiliki ukiran lebih rumit, ukuran lebih lebar, anjuang pada kedua ujung rumah, serta dihiasi dengan pahatan dengan warna yang berbeda, sebagian merah, putih, hitam, kadang-kadang biru, dan dilengkapi susunan cermin secara beraturan (Joustra, 1923: 154; Kato, 2005: 52; Boomgaard, 1929: 26).

Kedatangan bangsa Eropa ke Sumatera Barat pada abad ke-19, telah mengubah ciri dari bangunan rumah 
gadang. Sejak saat itu, masyarakat Minangkabau cenderung menggunakan seng sebagai bahan dasar atap (Boomgaard, 1929: 22-27). Menurut laporan seorang petualang, atap seng sudah banyak digunakan oleh orang-orang kampung di Minangkabau sekitar tahun 1907 (Kiyono, 1943: 283 dalam Kato, 2005: 39). Selain itu, kolonialisasi juga mempengaruhi motif-motif hiasan yang digunakan. Umumnya, bagian depan dihiasi dengan berbagai ukiran warnawarni, biasanya memiliki motif tumbuhtumbuhan. Selain itu, ditemukan peralatan rumah tangga bergaya Eropa, seperti meja, kursi, dan lampu minyak. Sebagian besar dari peralatan tersebut dibuat sendiri dengan menggunakan bahan-bahan alam, di antaranya bambu, kayu, tanduk, kulit binatang, logam, besi, tembaga, dengan dekorasi dan warna yang berbeda (Joustra, 1923: 157). Namun, pengaruh Barat hanya terjadi pada rumah-rumah orang kaya, kepala, dan pejabat pribumi.

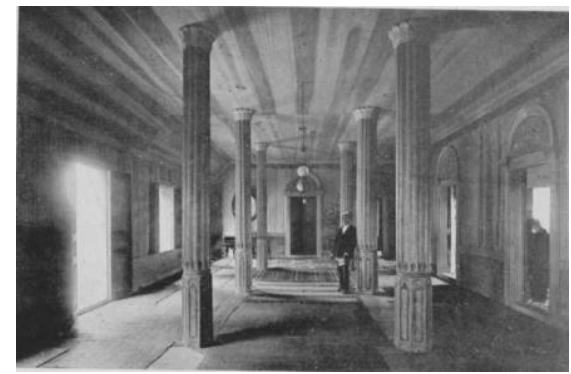

Gambar 2 Tengah Rumah Gadang Sulaiman Datuak Tumangguang Sumber: Joustra, M, 1923; 112

Pengaruh Eropa ditemukan pada bangunan Rumah Gadang Sulaiman Datuak Tumangguang, Kepala Laras Sungai Puar (1870-1930) (Gambar 1). Rumahnya merupakan salah satu bangunan termewah saat itu. Selain mendapatkan gaji sebesar f.80,- per bulan, seorang kepala laras juga mendapatkan tunjangan perbaikan rumah sebesar f.25,- per bulan sehingga tidak mengherankan jika rumahnya berbeda dengan masyarakat Minangkabau lainnya. Ia mengizinkan orang-orang asing mengunjungi kediamannya dan diabadikan dalam bentuk foto. Pada 1895, seorang ilmuan Jerman menjelaskan keadaan arsitektur bangunan Rumah Gadang Sulaiman Datuak Tumangguang dengan mengambil foto kamar utama. Ia mendeskripsikan bahwa ruangan tersebut memiliki tiang-tiang yang diukir, lampu-lampu minyak yang mengantung, dan klavir antik yang ditempatkan di sudut. Foto yang hampir sama juga diambil Joustra sekitar tahun 1920 (Gambar 2) (Hadler, 2008: 89-91; Asnan, 2006: 91).

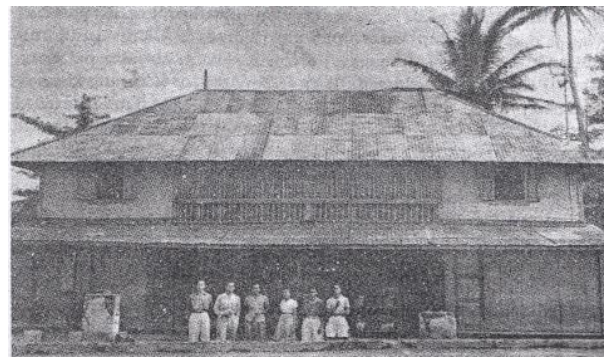

Gambar 3. Rumah Kelahiran Mohammad Hatta Sumber: Hatta, 1982: 7

Berbeda dengan elite tradisional, Haji Agus Salim dan Sutan Sjahrir sejak kecil hidup di rantau sehingga mengharuskan mereka tinggal di lingkungan Eropa. Sementara itu, Hatta tinggal di Bukittinggi, rumahnya terbuat dari papan, menggunakan atap seng, dan memiliki dua tingkat, seperti Gambar 3 (Hatta, 1982: 2).

\section{c) Bahasa dan Etika}

Masyarakat
gunakan Bangkabau mengberkomunikasi. Menurut penelitian ilmu bahasa, Bahasa Minang dianggap sebagai rumpun Bahasa Melayu, namun telah mengalami perubahan dari bentuk asli, terutama berkaitan dengan dialek dan bunyi (Graaf \& Stibbe, 1919: 494). Pada masa Pemerintahan Hindia Belanda, Bahasa Melayu digunakan sebagai bahasa pengantar pada sekolah Melayu dan bumiputra lainnya (Zulqayyim, 2006: 8283). Menurut surat pemberitahuan dari s.p.t Directeur van Onderwijs en Eeredienst pada 13 Maret 1831 no. 10152/D, Bahasa Minang dipakai dalam pengajaran sekolahsekolah nagari, sekolah-sekolah 
gouvernement di Sumatra's Westkust, dan Normal School di Padang Panjang. Oleh karena itu, mulai tahun ajaran 1933/1934 pemerintah menerbitkan kamus bahasa Minang (Soeloeh Agam, Mei 1934).

Sejak 1 Maret 1873, Bahasa Belanda mulai diajarkan kepada muridmurid Kweekschool di Fort de Kock. Namun, pada 1894 mata pelajaran Bahasa Belanda dihapuskan dan secara resmi diajarkan kembali pada 1904 (Friederich, 1908: 17- 28; Zulqayyim, 2006: 96). Dalam perkembangannya, menjelang abad ke-20, Bahasa Belanda dijadikan salah satu persyaratan agar bisa menjadi pegawai sipil (Graves, 2007: 213). Bahkan, keluarga Haji Agus Salim menjadikan Bahasa Belanda sebagai bahasa ibu. Ia mengajak dan mengajarkan anak-anaknya untuk berbicara menggunakan bahasa Belanda sejak lahir. Setelah berumur 3-4 tahun, mereka hanya menggunakan bahasa tersebut sebagai alat untuk berkomunikasi (Panitia Buku Peringatan: 1984: 53). Berbeda dengan Yahja Datuak Kayo, sebagai seorang pejabat pemerintah kolonial, ia cenderung menggunakan Bahasa Melayu daripada Bahasa Belanda. Ia menggunakan Bahasa Melayu (Indonesia) dalam pidato perdananya pada sidang Volksraad periode 1927-1931. Bahasa tersebut tidak lazim bagi anggota Volksraad yang berasal dari kalangan bumiputra pada saat itu. Selain itu, pada 1921-1923, Haji Agus Salim juga menggunakan Bahasa Indonesia dalam pidatonya, tetapi mendapat peringatan dari Tuan Voorzitter. Oleh karena itu, dalam karyanya, Azizah Etek, Mursyid A.M, dan Arfan B.R menjelaskan bahwa Haji Agus Salim dan Yahja Datuak Kayo disebut sebagai perintis penggunaan Bahasa Indonesia (Etek, et al., 2008: 29-32).

Bahasa Minangkabau memiliki empat jenis tutur kata (kato nan ampek), yaitu kato mandaki (kata mendaki) digunakan kepada orang yang lebih tua, kato manurun (kata menurun) kepada yang lebih muda, kato malereng (kata melereng) kepada orang yang disegani, dan kato mandata (kata mendatar) kepada teman sebaya. Meskipun demikian, di daerah ini tidak dikenal bahasa bangsawan dan bahasa rakyat. Perbedaannya hanya terdapat pada cara pemakaian yang ditentukan oleh lawan berbicara sehingga bahasa Minangkabau tidaklah egaliter (Navis, 1986: 101-102; Oktavianus \& Ike Revita, 2013: 26-31). Selain itu, tata karma masyarakat Minangkabau juga dapat diperhatikan dari cara berpakaian.

Dalam kehidupan sehari-hari, baik di tempat kerja maupun di rumah, umumnya laki-laki di Minangkabau menggunakan pakaian sederhana, terdiri atas penutup kepala, jaket atau jas, ikat pinggang, celana, dan saputangan (Joustra, 1923: 162; Graaf \& Stibbe, 1919: 384). Dalam perkembangannya, saat menduduki jabatan pemerintah kolonial, mereka cenderung menggunakan pakaian yang lebih kurang hampir mirip dengan bangsa Eropa.

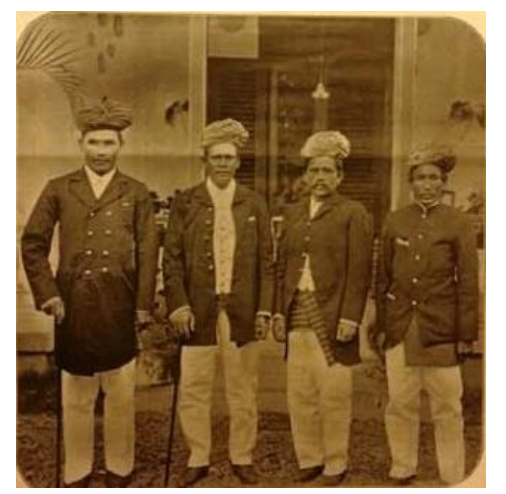

Gambar 4 Utusan Minangkabau dalam Kunjungan ke Pulau Jawa

Sumber: Bintang Hindia, 1 Juni 1907: 38

Pakaian yang digunakan menjelaskan status politiknya sebagai pejabat Pemerintahan Hindia Belanda dan pemimpin sukunya. Hal tersebut mengakibatkan mereka berbeda dengan masyarakat pada umumnya. Situasi tersebut dapat diperhatikan dari kunjungan pejabat pribumi Minangkabau ke Jawa pada awal abad ke-20, Angku Datuak Batuah (Kepala Laras Tilatang), Angku Datuak Bandaharo Pandjang (Kepala Laras Banoeahampoea), Angku Datuak Kayo (Kepala Laras IV Koto), dan Angku 
Mas Warido (Menteri Kopi kelas I Tilatang yang merangkap sebagai wakil Laras Mage' dan Salo) memakai pantalon putih (celana panjang putih), jas hitam, sepatu hitam, deta saluak (penutup kepala), serta dua di antaranya menggunakan sarung dan tongkat sebagai pelengkap pakaian, seperti Gambar 4 (Bintang Hindia, 1 Juni 1907: 38).

Perempuan Minangkabau tetap menggunakan pakaian asli, yang terdiri atas kain, baju, dan selendang (Gambar 5). Pangaruh Barat hanya terjadi pada bahan baku kain yang digunakan diimpor dari Eropa, seperti benang, kapas, dan lain-lain (Joustra, 1923: 170; Graaf \& Stibbe, 1919: 483).

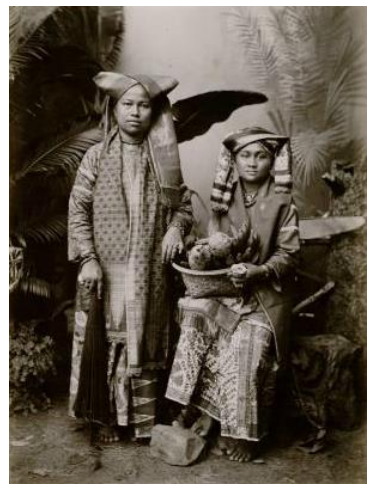

Gambar 5 Minangkabau vrouwen uit Koto Gadang (1895)

Sumber:media-kitlv.nl, kode foto 75252

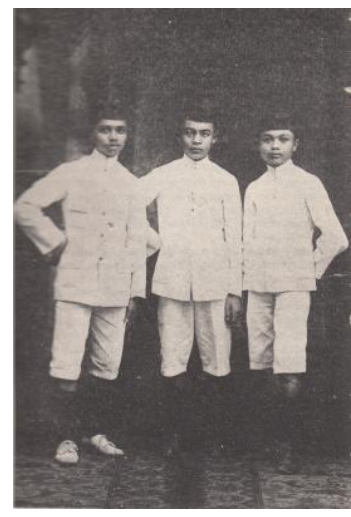

Gambar 6 Mohammad Hatta dan Dua Temannya Saat di Sekolah MULO Padang Sumber: Hatta, 1982: 37

Berbeda dengan elite tradisional, kaum intelektual lebih cenderung menggunakan pakaian bergaya Barat. Pakaian tersebut digunakan saat menempuh pendidikan Barat. Saat menempuh pendidikan di Meer Uitgebreid Lager Onderwijs (MULO), Hatta menggunakan seragam sekolah, terdiri atas kopiah (penutup kepala), baju putih, celana pendek putih, kaus kaki, dan sepatu, seperti Gambar 6. Sementara itu, dalam kesehariannya, Haji Agus Salim tetap menggunakan baju teluk benggala, pakaian khas dari Minangkabau (Panitia Buku Peringatan, 1984: 99).

\section{d) Pusaka dan Upacara}

\section{Kekayaan di Minangkabau} ditentukan oleh kepemilikan tanah keluarga. Harta, kekayaan, dan sumber penghasilan lainnya disebut harta pusaka atau pusako (Graves, 2007: 13). Setiap harta yang telah menjadi pusaka harus dijaga agar tetap utuh, tidak bisa diperjual belikan, dan dikuasai secara pribadi.

Menurut adat Minangkabau, harta pusaka terdiri atas, harta material dan harta moril. Adapun yang disebut sebagai harta material di antaranya sawah, ladang, rumah gadang, emas, perak, dan lain-lain. Sementara itu, gelar disebut sebagai harta moril yang diwarisi secara turun temurun (Sjarifoedin, 2011: 97). Pewarisan gelar Datuak Kayo dari Landjadin Khatib Besar kepada Yahya (kemenakannya) pada 1895 merupakan salah satu contoh dari harta pusaka moril. Namun, pada tahun yang sama ia juga menduduki jabatan Kepala Laras IV Koto, Oud Agam (Etek, et al., 2007: 189). Berbeda dengan gelar datuak yang diterimanya, jabatan kepala laras diberikan berdasarkan pertimbangan Pemerintahan Hindia Belanda dan tidak bisa diwariskan kepada generasi berikutnya.

Pewarisan gelar di Minangkabau dilakukan dengan serangkaian upacara adat yang dikenal dengan batagak pangulu. Upacara tersebut diadakan di lapangan terbuka dan perjamuan berlangsung selama tiga hari berturut-turut (Navis, 1986: 146147). Selain itu, dikenal upacara perkawinan, kematian, batagak rumah 
(mendirikan rumah), khatam Al-Qur'an, dan hari raya.

Khatam Qur'an (manamaikan kaji) dilakukan jika seorang anak laki-laki atau perempuan sudah bisa membaca Al-Qur'an dan menyelesaikannya. Dalam perayaan tersebut si anak berpakaian layaknya seorang haji yang baru pulang dari Mekah. Acara berlangsung pada pagi, dimulai dengan arak-arakan sepanjang jalan kampung, dilanjutkan dengan membaca Al-Qur'an dan ditutup dengan makan besar, seperti Gambar 7 (Suryadi, 2016).

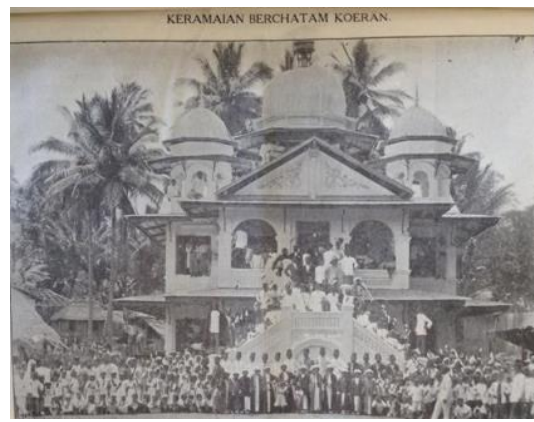

Gambar 7 Keramaian Khatam Al-Qur'an di Batipuh, Padang Panjang

Sumber: Pandji Poestaka, 12 Februari 1926.

\section{e) Pendidikan}

Sebelum berdirinya sekolah sebagai pendidikan formal di Minangkabau, dikenal surau sebagai lembaga pendidikan Islam. Pada prinsipnya surau berfungsi untuk mensosialisasikan nilai-nilai agama Islam kepada anak-anak Minangkabau. Kemudian, pada 1848 Steinmetz mendirikan Sekolah Melayu (Malaische School) di Bukittinggi. Sekolah tersebut merupakan pendidikan formal pertama di Bukittinggi dan Dataran Tinggi Padang (Zulqayyim, 2006: 79-8; Steinmetz, 1850: 305). Namun, kontribusi utama pemerintah dalam pendidikan di Sumatera Barat dilakukan dengan pembangunan dan pendanaan Sekolah Raja (Kweekschool) di Bukittinggi pada 1856 (Graves, 2007: 218).

Perkembangan pendidikan di Sumatera Barat mendapat tanggapan yang berbeda dari elite tradisional dan elite intelektual di Afdeeling Agam. Minat paling tinggi terhadap pendidikan ditemukan pada keluarga golongan menengah dengan tradisi merantaunya (Graves, 2007: 202). Sulaiman Datuak Tumangguang memanfaatkan kedudukannya sebagai Kepala Laras Sungai Puar (1870-1930-an), dengan mengirim anaknya, Abdul Muis untuk melanjutkan sekolah ke Batavia (Azmi, 1981: 1-7). Cara yang berbeda dilakukan Landjadin Khatib Besar gelar Datuak Kayo dalam menentukan pendidikan kemenakannya, Yahja Datuak Kayo. Ia lebih banyak memperkenalkan Yahya kepada birokrasi Pemerintah Hindia Belanda daripada melanjutkan pendidikan Barat ke luar wilayah Minangkabau. Pada 1882, Yahya bersekolah di Pasar Gadang. Satu tahun kemudian, ia pindah ke Sekolah Privat Bukittinggi. Sebenarnya, ia memiliki kesempatan untuk mengikuti ujian di Sekolah Raja Bukittinggi, namun Landjadin Khatib Besar melarangnya. Alasannya sederhana, jika Yahya masuk ke Sekolah Raja, setelah lulus ia akan pergi jauh merantau ke nagari lain. Landjadin berkeinginan agar kemenakannya bisa menjadi pemimpin di Nagari Koto Gadang (Etek, et al., 2007: 187-189).

Berbeda dengan elite tradisional, Haji Agus Salim, Sutan Sjahrir, Abdul Muis, dan Mohammad Hatta memilih melanjutkan pendidikan formal ke luar wilayah Minangkabau. Haji Agus Salim memulai pendidikan dengan masuk ke Europeesche Lagere School (ELS), kemudian dilanjutkan ke Hogere Burger School (HBS) di Batavia (Panitia Buku Peringatan, 1884: 36-42). Sutan Sjahrir memulai pendidikan sekulernya saat berumur enam tahun. Pada 1915, ia masuk ELS di Medan. Kemudian, melanjutkan pendidikan ke MULO pada 1923 dan lulus pada musim panas tahun 1926. Pada 1927 ia melanjutkan pendidikan ke AMS Bandung (Mrazek, 1996: 34-63). Abdul Muis memulai pendidikan formalnya di Bukittinggi, kemudian melajutkan ke STOVIA pada 1902. Namun, setelah tiga 
tahun bersekolah, ia dikeluarkan karena enggan melihat darah. Sementara itu, pendidikan agama langsung diberikan keluarga saat berada di kampung halamannya (Azmi, 1981: 1-7). Hatta memulai pendidikan formalnya dengan belajar di Sekolah Belanda Preman Tuan Lederboer. Tujuh bulan kemudian, saat berumur enam tahun, ia masuk ke Sekolah Rakyat. Setelah dua tahun di Sekolah Rakyat hingga pertengahan kelas tiga, ia pindah ke Sekolah Belanda dan langsung diterima di kelas dua, sesuai dengan kemampuannya dalam berbahasa Belanda. Pada pertengahan 1913, Hatta pindah ke MULO Padang dan lulus pada Mei 1919. Kemudian melanjutkan pendidikan ke Prins Hendrik School dan Rotterdamse Handelshogeschool pada 1921. Meskipun demikian, saat tinggal di Bukittingi, pada siang harinya ia bersekolah dan setelah magrib belajar mengaji di Surau Syekh Djambek (Hatta, 1982: 22-136).

\section{f) Perkawinan}

Perkawinan ideal di Minangkabau terjadi antara awak samo awak (sesama keluarga dekat). Perkawinan dengan orang luar, terutama mengawini perempuan luar dianggap dapat merusak struktur adat. Sebaliknya, perkawinan perempuan Minang dengan laki-laki luar diperbolehkan karena tidak akan mengubah struktur adat, sehingga anak yang lahir tetap mengikuti suku yang ada di Minangkabau (Navis, 1986: 194-195).

Menurut suatu laporan pada tahun 1910-an, Nagari Koto Gadang memaksakan perkawinan antara kerabat (endogami) (Mrazek, 1996: 15). Oleh karena itu, sebagai salah satu elite tradisional terkemuka, Yahja Datuak Kayo mengikuti tipe perkawinan tersebut. Ia memiliki tiga istri. Pertama, Basiah dari Koto Gadang, merupakan anak mamaknya (pamannya) yang berusia tujuh tahun lebih tua. Kedua, Rusiah dari Padang. Ketiga, Syahrizan dari Koto Gadang dan menikah pada tanggal 20 Maret 1924. Pada pernikahannya yang ketiga, mempelai perempuan menggunakan pakaian khas Koto Gadang dengan baju kuruang dan tilakuang sebagai penutup kepala, sedangkan mempelai laki-laki menggunakan jas dan saluak sebagai penutup kepala, seperti pada Gambar 8 (Etek, et al., 2007: 257).

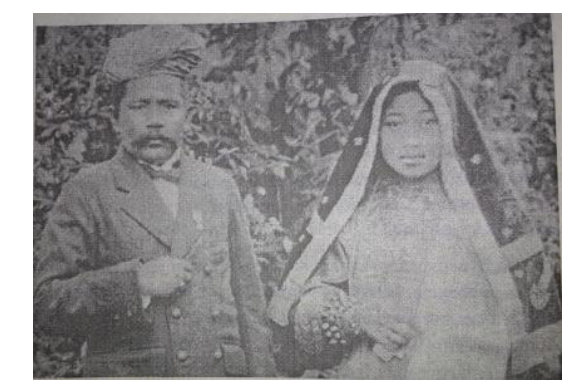

Gambar 8 Pernikahan Yahya Datuak Kayo dengan Syahrizan di Nagari Koto Gadang

Sumber: Etek, et al. 2007: 256

Sama halnya dengan Yahya Datuak Kayo, Haji Agus Salim tidak menolak untuk dikawinkan dengan saudara sepupunya berdasarkan adat Minangkabau. Perkawinan tersebut ideal menurut adat Minangkabau. Namun, tidak semua tradisi adat yang dijadikan sebagai acuan dalam upacara pernikahannya. Ia hanya menjalankan tradisi adat yang tidak bertentangan dengan ajaran agama Islam. Perhelatan berlangsung menurut tradisi adat, termasuk acara diaraknya kedua mempelai melalui jalan-jalan kampung dan diiringi dengan bunyi-bunyian dari rebana. Saat upacara berlangsung, Haji Agus Salim menggunakan pakaian marapulai (mempelai pria) berwarna merah dan kuning keemasan, serta dilengkapi dengan sorban sebagai penutup kepala. Sementara itu, mempelai wanita menggunakan baju kuruang dan tilakuang sebagai penutup kepala khas dari Koto Gadang. Namun, prinsip tersebut tidak berlaku bagi anakanaknya. Ia menginginkan kedelapan anaknya menikah dengan orang di luar Nagari Koto Gadang. Menurut Agus Salim, perkawinan dengan keluarga dekat tidak menguntungkan dari segi keturunan. Hal tersebut dilakukan untuk menghindari degenerasi pemurnian darah yang 
dialaminya (Panitia Buku Peringatan, 1984: 46- 51 \& 97).

\section{g) Kesenian dan Permainan}

Berbagai macam permainan membedakan antara hiburan bagi anakanak dan orang tua. Umumnya, anak-anak di Minangkabau mengisi waktu luang dengan bermain gasiang (gasing), alangalang (layang-layang), berjalan menggunakan batok kelapa, permainan katai (menggunakan dua tongkat), kelereng (menggunakan buah kemiri), pertengkaran, latihan perang, petak umpet, atau menirukan orang dewasa; perempuan bermain congklak; dan laki-laki bermain catur. Meskipun demikian, seseorang yang bermainan sepak rogo (sejenis sepak bola) di laun-alun akan mendapat kehormatan besar. Permainan tersebut menggunakan bola anyaman dan ditendang dari satu pemain ke pemain yang lain (Joustra, 1923: 172-173). Selain itu, dikenal berbagai jenis tarian, seperti ilau, tari salendang panjang, adau-adau, tari piriang (tari piring), dan randai.

Tari piring merupakan salah satu kesenian yang berasal dari Luhak Agam. Tarian tersebut dimainkan secara tunggal atau bersama-sama dengan meletakkan piring porselen di telapak tangan dan cincin di ujung jari tengah. Cincin dan piring porselen digerakkan secara bersamaan hingga menghasilkan bunyi. Sementara itu, kaki membentuk hentakan dan membuat lingkaran. Gerakan tersebut mengimprovisasi elang terbang; petani membajak dan mencangkul; gadis berhias; perempuan menjahit dan menenun; dan lain-lain. Setiap gerakan dilakukan secara berulang hingga sebuah pantun selesai dinyanyikan atau satu gerakan memerlukan satu empat kali dalam empat ketukan. Adakalanya, jika tarian tersebut dimainkan pada malam hari, penari memasang lilin di kedua piring. Tarian tersebut dimainkan dalam suasana ceria, misalnya saat dilakukan sunat rasul (sunatan), pernikahan, perkawinan, dan anak turun mandi (Oetoesan Minangkabau: Sasaran
Penghoeloe, Medan Ra'jat, Februari 1939: 3 \& 39; Navis, 1986: 270- 271 ).

Berbeda dengan elite tradisional, kesenian dan permainan para elite intelektual lebih menirukan gaya Barat. Pada saat menempuh pendidikan Barat, mereka tidak hanya dididik dalam berbagai mata pelajaran, namun juga cara bersikap dan sopan santun. Keadaan tersebut bisa diperhatikan dari keseharian para elite intelektual dalam mengisi waktu luang di sela-sela kesibukannya sebagai seorang pelajar. Sjahrir mengisi waktu luangnya dengan bermain bola dan bermain musik (Mrazek, 1996: 38, 60-61). Sementara itu, Hatta lebih memilih bermain sepak bola dan menonton ke bioskop (Hatta, 1982: 32-33).

\section{h) Cara Makan}

Makanan

masyarakat

Minangkabau bisa disebut sederhana. Nasi merupakan bahan makanan utama dan tepung beras dijadikan untuk membuat kue, kecuali pada acara-acara khusus mereka memiliki jenis makanan lain selain nasi. Biasanya nasi dimakan tiga kali sehari, pada pagi, siang, dan malam. Selain itu, dikenal bahan makanan pokok berupa sagu, anau palm, sagu palm (roembio), jagung, sakoei (gula merah), dan berbagai jenis sereal yang tidak dikenal. Mereka juga mengkonsumsi ubi dan umbi-umbian, berbagai jenis terung, tomat, mentimun, kacang, daun matung, bayam, petai, dan jengkol. Sementara itu, sebagai pelengkap nasi digunakan lauk pauk. Dalam hal ini, kata lauk memiliki ekpresi kiasan. Untuk daerah pedalaman, kata tersebut berarti daging dan di daerah pesisir berarti ikan. Untuk itu, di wilayah ini lauk pauk kering disebut dengan samba-samba, sedangkan lauk pauk yang terdiri atas saus atau sup disebut gulai-gulai (Joustra, 1923: 175).

Jika dilihat dari waktunya, anggota dalam sebuah rumah gadang memiliki waktu makan yang berbeda antara satu dan yang lainnya. Perempuan yang tidak bersuami makan di ruangan dekat dapur dan perempuan yang bersuami makan 
bersama suaminya masing-masing di ruang tepat di hadapan kamar sendiri. Sementara itu, makan secara bersama hanya dilakukan saat kenduri yang diadakan rumah tersebut (Navis, 1986: 180).

Sama halnya dengan elite tradisional, elite intelektual juga menggunakan nasi sebagai makanan pokok. Perbedaannya terdapat pada cara pengolahan dan bahan pelengkap nasi yang dipengaruhi budaya Barat. Keadaan tersebut dapat diperhatikan dari kehidupan keluarga Haji Agus Salim yang menetap di rantau. Mereka tidak hanya mengenal daging dan ikan sebagai lauk pauk, tetapi juga menggunakan kecap, susu, mentega, dan keju sebagai pelengkap nasi. Selain itu, mereka telah mengenal nasi goreng (Panitia Buku Peringatan, 1984: 80-81).

\section{i) Agama dan Kepercayaan}

Elite Minangkabau di Afdeeling Agam menganut agama Islam. Yahya Datuak Kayo, Sulaiman Datuak Tumangguang, Haji Agus Salim, Mohammat Hatta, Sutan Sjahrir, dan Abdul Muis beragama Islam. Mereka mendapatkan pendidikan agama dari lingkungan keluarga sejak kecil. Haji Agus Salim memperdalam pengetahuan agama Islam pada usia 22 tahun, saat ia menjabat sebagai dragman (ahli penerjemah) Konsultan Belanda di Arab (Panitia Buku Peringatan, 1984: 43-44). Sutan Sjahrir dan Mohammad Hatta belajar mengaji setelah menempuh pendidikan Barat pada pagi hari (Mrazek, 1996: 40; Hatta, 1982; 1982). Abdul Muis memilih gerakan politik berdasarkan agama Islam (Azmi, 1982:6). Sementara itu, Yahja Datuak Kayo menjalankan hukum adat dan hukum Islam secara bersamaan. Dalam pidatonya pada Mei 1939, dijelaskan mengenai fenomena adat dan agama di Minangkabau tentang harta warisan. Ia berbicara dari sudut pandang adat dan agama, seolah-olah keduanya bertentangan. Namun, sebagai umat Islam, ia sepenuhnya harus mengerjakan agama Islam dan mengikuti semua peraturan adat Minangkabau (Etek, et al., 2007: 249-255).

\section{PENUTUP}

Berdasarkan uraian di atas, dapat disimpulkan bahwa gaya hidup elite Minangkabau di Afdeeling Agam tidak banyak mengalami perubahan, melainkan terjadi akulturasi antara budaya asli Minangkabau dengan budaya Barat. Dalam hal ini, gaya hidup elite tradisional dan elite intelektual memiliki beberapa perbedaan, diperhatikan dari nama dan gelar, tempat tinggal, etika dan bahasa, pusaka dan upacara, pendidikan, perkawinan, kesenian dan permainan, cara makan, serta agama dan kepercayaan.

Elite tradisional Minangkabau di Afdeeling Agam menggunakan nama dan gelar berdasarkan aturan adat Minangkabau, tinggal di rumah gadang, berbahasa Minang, menggunakan pakaian mirip bangsa Eropa dengan ciri khas Minangkabau, menempuh pendidikan di wilayah Minangkabau dan mengisi waktu luang dengan berbagai kesenian dan permainan tradisional Minangkabau. Sementara itu, elite intelektual tidak menggunakan gelar kebesaran datuak, tinggal dan menetap di luar wilayah Minangkabau (merantau), menempuh pendidikan formal di luar wilayah Minangkabau, dan mengisi waktu luang dengan kesenian dan permainan Eropa. Meskipun demikian, baik elite tradisional maupun elite intelektual di Afdeeling Agam pada masa Pemerintahan Hindia Belanda sama-sama memeluk agama Islam dan melaksanakan tradisi adat Minangkabau hingga saat ini.

Untuk kajian lebih lanjut, diperlukan penelitian daerah lain di Sumatera Barat. Hal ini sebagai bahan perbandingan sehingga menghasilkan karya yang lebih lengkap.

\section{UCAPAN TERIMA KASIH}

Penulis mengucapkan terimakasih kepada Prof. Dr. Nina Herlina Lubis, M.S. dan Dr. R.M. Mulyadi yang telah 
memberikan arahan dan bimbingan dalam penelitian ini. Terima kasih juga penulis ucapkan kepada staf Perpustakaan Nasional Republik Indonesia (PNRI), Arsip Nasional Republik Indonesia (ANRI), Perpustakaan FIB UNPAD, Perpustakaan Daerah Provinsi Sumatera Barat, Perpustakaan UNAND, Perpustakaan UNP, Pusat Dokumentasi dan Informasi Budaya Minang (PDIKM), dan semua pihak yang telah membantu dalam pengumpulan sumber pada penelitian ini.

\section{DAFTAR SUMBER}

\section{Arsip dan Dokumen Tercetak}

Regeeringsalmanak voor Nederlandsch-Indie. 1884-1942. Eerste Gedeelte. Batavia: Landsdrukkerij.

Volkstelling 1930; deel IV Inheemsche Bevolking van Sumatra. 1935. Batavia: Departement van Economische Zaken.

\section{Disertasi}

Manan, Imran. 1984.

A Traditional Elite in Continuity and Change; The Chief of the Matrilineal Lineages of the Minangkabau of West Sumatra, Indonesia. Thesis Doctor of Philosophy. University of 1llinois at Urban Champaign.

\section{Buku}

Asnan, Gusti. 2003.

Kamus Sejarah Minangkabau. Padang: Pusat Pengkajian Islam dan Minangkabau.

2006.

Pemerintahan Sumatera Barat dari VOC hingga Reformasi. Yogyakarta: Citra Pustaka.

Amran, Rusli. 1986. Sumatera Barat Plakat Panjang. Jakarta: Sinar Harapan.

Azmi. 1982.

Abdul Muis. Jakarta: Departemen Pendidikan dan Kebudayaan, Direktorat Sejarah dan Nilai Tradisional, Proyek Inventarisasi dan Dokumentasi Sejarah Nasional.

Bottomore, T.B. 2006.
Elite dan Masyarakat. Terj. Jakarta: Akbar Tandjung Institute.

Ensiklopedi Nasional Indonesia Jilid 1. 1988. Jakarta: Cipta Adi Pustaka.

Etek, Azizah; Mursyid; dan Arfan. 2007. Koto Gadang Masa Kolonial. Yogyakarta: LKiS Pelangi Aksara. 2008.

Kelah Sang Demang Jahja Datoek Kajo; Pidato Otokritik di Volksraad 19271939. Yogyakarta: LKiS Pelangi Aksara.

Friederich, R. 1908.

Gedenkboek samengesteld bij gelegenheid van het 35jaring bestaan der Kweekschool voor Inlandsche Onderwijzers te Fort de Kock. Arnheim: Threme.

Gottschalk, Louis. 2008. Mengerti Sejarah. Terj. Nugroho Notosusanto. Jakarta: UI-Press.

Graaf, S.de dan Stibbe, D.G (ed). 1919. Encyclopaedie van Nederlandsch Indie. 's.Gravenhage: Martinus Nijhoff.

Graves, Elizabeth E. 2007.

Asal Usul Elite Minangkabau Modern; Respon terhadap Kolonial Belanda Abad XIX/XX. Terj. Jakarta: Yayasan Obor Indonesia.

Hadler, Jeffrey. 2008. Sengketa Tiada Putus; Matriarkat, Reformisme Islam, dan Kolonialisme di Minangkabau. Terj. Jakarta: Freedom Institute.

Hatta, Mohammad. 1982. Mohammad Hatta; Memoir. Jakarta: Tintamas Indonesia.

Herlina, Nina. 2008. Metode Sejarah. Bandung: Satya Historika.

Josselin, de Jong P.E. 1975. Social Organization of Minangkabau. Leiden: University of Leiden.

Joustra, M. 1923.

Minangkabau Overzicht van Land, Geschiedenis en Volk. Martinis Nijhoff 'S-Gravenhage.

Junus. 1999. 
“Kebudayaan Minangkabau”, dalam Koentjaraningrat (ed.). Manusia dan Kebudayaan di Indonesia. 1999. Jakarta: Djambatan. Hlm. 248-265.

Kartodirdjo, Sartono; A.Sudewo; dan Suhardjo Hatmosuprobo. 1993.

Perkembangan Peradapan Priyayi. Yogyakarta: Gadjah Mada University Press.

Kuntowijoyo. 2013.

Pengantar Ilmu Sejarah. Yogyakarta: Tiara Wacana.

Kato, Tsuyoshi. 2005.

Adat Minangkabau dan Merantau dalam Perspektif Sejarah. Terj. Jakarta: Balai Pustaka.

Lubis, Nina H. 1998.

Kehidupan Kaum Menak Priangan 1800-1942. Bandung: Pusat Informasi Kebudayaan Sunda.

Mansoer, M.D.; Amrin Imran; Mardanas Safwan; Asmaniar Z. Idris; dan Sidi I. Buchari. 1970.

Sedjarah Minangkabau. Jakarta: Bhratara.

Mrazek, Rudolf. 1996 Sjahrir; Politik dan Pengasingan di Indonesia. Terj. Jakarta: Yayasan Obor Indonesia.

Navis, A.A. 1986.

Alam Terkembang Jadi Guru; Adat dan Kebudayaan Minangkabau. Jakarta: Temprint.

Oktavianus dan Ike Rivita. 2013. Kesantunan dalam Bahasa Minangkabau. Padang: Minangkabau Press.

Panitia Buku Peringatan. 1984 Seratus Tahun Haji Agus Salim. Jakarta: Sinar Harapan.

Reid, Anthony. 2012. Sumatera; Revolusi dan Elite Tradisional. Jakarta: Komunitas Bambu.

Sjarifoedin, Amir. 2011.

Minangkabau; dari Dinasti Iskandar Zulkarnain sampai Tuanku Imam Bonjol. Jakarta: Gria Media Prima.
Boekittinggi Tempo Doeloe. Padang: Andalas University Press.

\section{Surat Kabar dan Artikel}

"Baso (Tjaro) Minangkabau". Soeloeh Agam, Mei 1934, No 5, hlm 1-2.

Boomgaard, S.

"Het Adathuis In Minangkabau", Onze Aarde Geillustreerd Maandschrift. 1929, hlm. 22-28.

Joustra, M.

"De Minangkabausche Maleiers; Naar gegevens van Amaroellag Galar Soetan Mangkoeto Bewerkt". In de Volken van Nederlandsch-Indie, 1920, hlm. 151176.

"Kermaian Berchatam Koeran". Pandji Poestaka, 12 Februari 1926, No. 12, Tahun IV, hlm. 263.

"Kesenian (Kunst dan Cultuur) Minangkabau; Tari-Pentjak-Silat Jang Asli". Oetoesan Minangkabau; Sasaran Penghoeloe, Medan Ra'jat, 20 Februari 1939. No. 3. Tahun 1, hlm. 38.

Mansveld, G.

"Namen en Galars Onder de Maleijer in de Padangsche Bovenlanden; bepaaldelijk in Noordelijk Agam". Tijdschrift Bataviaasch Genootschap, 1876. hlm. 442-457.

"Oetoesan Orang Minangkabau". Bintang Hindia, 1 Juni 1907, No. 4. Tahun V1, hlm. 38-39.

Steinmetz, H.E.

"Inlandsche Onderwijs van Overheidswege in de Padangsche Bovenlanden voor 1850". BKI No.64 Tahun 1924, hlm. 301-312.

\section{Internet}

"Minangkabau vrouwen uit Koto Gadang" diakses dari media-kitlv.nl (kode foto 75252), Tanggal 31 Agustus 2016, Pukul 10.45 WIB.

Zulqayyim. 2006. 